\title{
THE ROLE OF THE SEED COAT IN THE LIGHT SENSITIVITY IN RAPHANUS SATIVUS L. CV. REDONDO GIGANTE SEEDS
}

\author{
Maura Lúcia Costa Gonçalves ${ }^{1}$ \\ Massanori Takaki ${ }^{1}$
}

Recebido em 20/11/96. Aceito em 13/6/97

RESUMO - (O papel do tegumento na sensibilidade à luz em sementes de Raphanus sativus $\mathrm{L}$. cv. redondo gigante). O papel do tegumento sobre a sensibilidade à luz em sementes de Raphanus sativus $\mathrm{L}$. cv. redondo gigante foi analisado por testes de germinação de sementes intactas e nuas. A luz vermelho-extremo inibiu fortemente a germinação, enquanto as luzes branca e vermelha apresentaram baixa inibição. Por outro lado, sementes nuas não apresentaram sensibilidade à luz, com alta porcentagem de germinação tanto na luz como no escuro. Entretanto, a incubação das sementes nuas em condiçōes de estresse em solução de polietilenoglicol a $-0,6 \mathrm{MPa}$, resultou em inibição na luz, como observadas em sementes intactas. A análise da luz transmitida pelo tegumento das sementes indicou que a luz filtrada apresenta o mesmo fotoequilibrio teórico do fitocromo obtido na luz branca, com um decréscimo em apenas $33 \%$ da irradiância que atinge o embrião.

Palavras-chave: germinaçāo de sementes, Raphanus sativus, tegumento, fitocromo

ABSTRACT - (The role of the seed coat in the light sensivity in Raphanus sativus L. cv. redondo gigante seeds). The role of the seed coat in the light sensitivity of seeds of Raphanus sativus L. cv. redondo gigante was analysed by germination tests of intact and naked seeds. Far-red light caused high inhibition of seed germination, while under white and red lights low inhibition was found. Naked seeds presented no light sensitivity with high percentage germination under light and darkness. However, incubation of naked seeds in - $0.6 \mathrm{MPa}$ polyethylene glycol solution resulted in light inhibition as observed in intact seeds. The analysis of the seed coat transmitted light indicated that the filtered light presented the same photoequilibrium of phytochrome when compared to the white light, with a decrease of only $33 \%$ in the light irradiance which reaches the embryo.

Key words: seed germination, Raphanus sativus, seed coat, phytochrome

\footnotetext{
${ }^{1}$ Departamento de Botânica. UNESP, C.P. 199, CEP 13506-900. Rio Claro, SP, Brasil
} 


\section{Introduction}

The germination of seeds of Raphanus sativus is controlled by light under water stress conditions (MacDonough 1967) and Ladeira et al. (1987) have proposed that the phytochrome is used by plants as a transducer of soil water potential. Freitas \& Takaki (1992) have proposed the involvement of phytochrome in the control of germination in light insensitive seed of $R$. sativus under water stress conditions, therefore observing the fluence dependent inhibition of seed germination by far red (FR), red (R) and white light, with highest inhibition by FR light. Barbarini \& Takaki (1989), working with Phaseolus vulgaris, observed high light sensivity after osmotic treatment, indicating changes in the mode of phytochrome action. Takaki \& Toledo (1991), working with seeds of Oryza sativa, also observed that scarified seeds germinated both in light and darkness under water stress conditions.

The role of the seed coat in the control of seed germination was analysed in several weedy species by Felippe \& Polo (1983), demonstrating that light sensitivity is lost after scarification in both positive and negative photoblastic seeds. Cardoso \& Felippe (1988), working with negative photoblastic seeds of Cucumis anguria, have proposed that after analysis of light transmitted by seed coat, enrichment with FR light is responsible for white light inhibition of seed germination. However, the spectrum analysis of the seed coat transmitted light indicated that the photoequilibrium of 0.68 is maintained by fluorescent white light. The same effect was reported by Leite \& Takaki (1994) in seeds of Piptadenia gonoacantha in which decrease in $6 \%$ of photoequilibrium of phytochrome in the region of the embryo was observed.

In the present work we describe the role of the seed coat in the light sensitivity of seeds of Raphanus sativus L. cv. redondo gigante.

\section{Material and methods}

Seeds of Raphanus sativus L. cv. redondo gigante used in the present work were purchased in a local seed shop. The germination condition was the same as described by Ladeira et al. (1987), where four batches of thirty seeds were put on two layers of imbibed filter papers with water or polyethylene glycol 6000 (PEG) solution in 90mm Petri dishes. The water potential of PEG solutions were calculated according to Michel (1983). The light conditions were also the same as described by Ladeira et al. (1987). Darkness conditions were obtained by wrapping the dishes with two layers of aluminum foil. All the germination tests were carried out at $25^{\circ} \mathrm{C}$. Scarification of seeds was carried out by remotion of the seed coat by hand in 6 hours water imbibed seed. Seeds were considered as germinated when showed a root of $2 \mathrm{~mm}$ at least, and dark germinated seeds were counted under dim green safe light (Kendrick \& Frankland 1969). Each experiment was repeated at least twice, with similar results.

The spectrum of seed coat transmitted light was obtained by the remotion of the seed coat of 6 hours water imbibed seeds pressed inside two microscope glass slides, with a $2 \mathrm{~mm}$ diameter hole in a black card put on the remote sensor of a LI-1800 
spectroradiometer (LI-COR, U.S.A.) positioned under fluorescent white light. The light spectra were analysed using the PC1800 software (LI-COR, USA). The theoretical photoequilibrium of the phytochrome was calculated using the following equation: $\varphi=0.87 /(1+(0.295 / \zeta))$, where, $\varphi=$ photoequilibrium of the phytochrome and $\zeta=$ irradiance at $655-665 \mathrm{~nm} /$ irradiance at $725-735 \mathrm{~nm}$ (Mancinelli 1994). The results were submitted to the Tukey test at $5 \%$ significance level of $\operatorname{arc} \sin \sqrt{\% / 100}$.

\section{Results and discussion}

Seeds of Raphanus sativus cv. redondo gigante germinate better under $25^{\circ} \mathrm{C}$ in darkness than under fluorescent white light, but naked seeds germinated both under dark and white light (Fig. 1). This effect was reported by Felippe \& Polo (1983) in photoblastic weedy seeds, where scarification resulted in germination under white light and darkness.

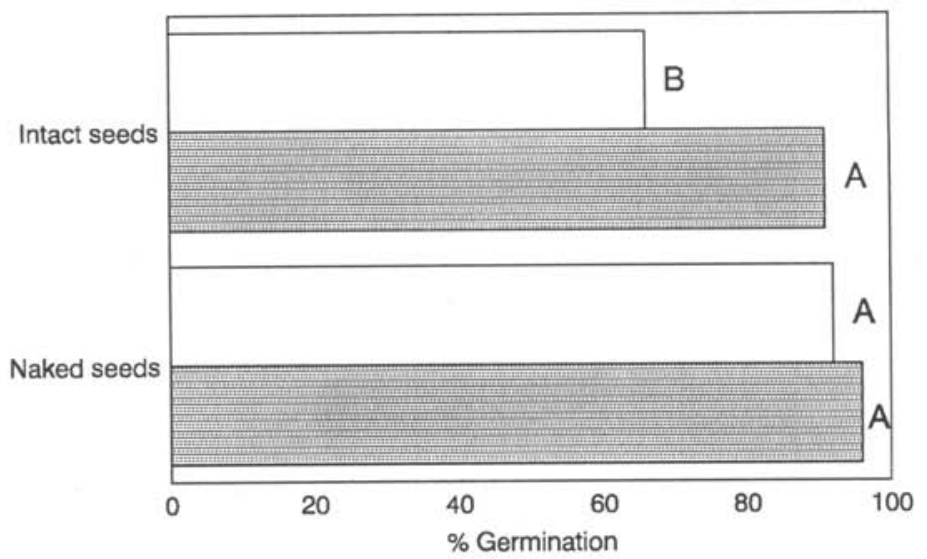

Figure 1. Effect of remotion of seed coat on the germination of Raphanus sativus L. cv. redondo gigante under white light $(\bullet)$ and darkness (ㅌ) $)$.

FR light caused high inhibition of germination of Raphanus sativus intact seeds while R light had the same effect of white light. However, light treatment had no effect in naked seeds, with high germination rates (Fig. 2). Similar results were reported by Freitas \& Takaki (1992) in light insensitive batch of cultivar redondo gigante after water stress.

Incubation of intact and naked seeds under $-0.6 \mathrm{MPa}$ PEG solution resulted in inhibition by light treatments, with the highest inhibition rates in intact ones (Fig. 3). These results indicate that water stress has had the same effect of the seed coat restoring the light sensitivity of radish seeds. 


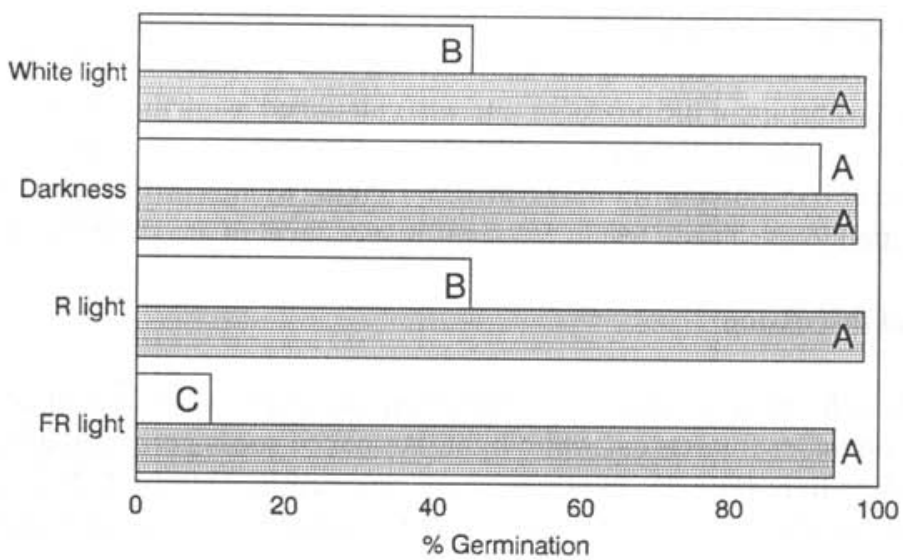

Figure 2. Effect of light quality treatment on seed germination of Raphanus sativus $\mathrm{L}$. cv. redondo gigante. Intact $(\bullet)$ and naked $($ 曼 $R=$ red and $F R=$ far-red.

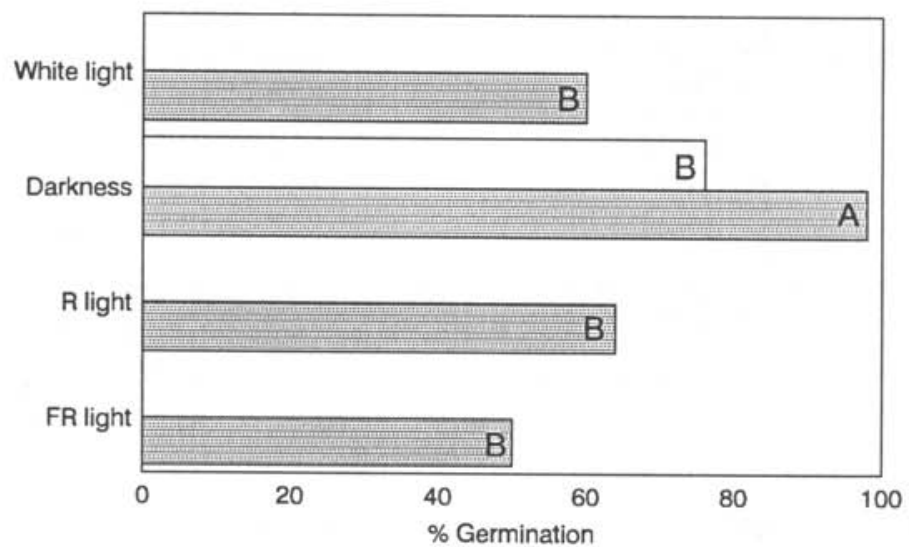

Figure 3. Effect of incubation of intact $(\bullet)$ and naked $(\mathbb{G})$ seeds of Raphanus sativus $\mathrm{L}$. cv. redondo gigante under $-0.6 \mathrm{MPa}$ solution of PEG on seed germination under different light qualities.

The seed coat transmitted light analysis indicates that $R / F R$ ratio is 3.34 while of the white fluorescent is 3.75 . The theoretical photoequilibrium of phytochrome indicates that white light maintains 0.806 of Pfr while seed coat filtered light maintains 0.799 of Pfr. These results indicate that the seed coat did not change the light quality but only the light irradiance of 1.646 found in the fluorescent white light to $0.543 \mathrm{~W} \cdot \mathrm{m}^{-2}$ of seed coat filtered light (Fig. 4). In other words the seed coat decreases in $33 \%$ the light irradiance that reaches the embryo. 


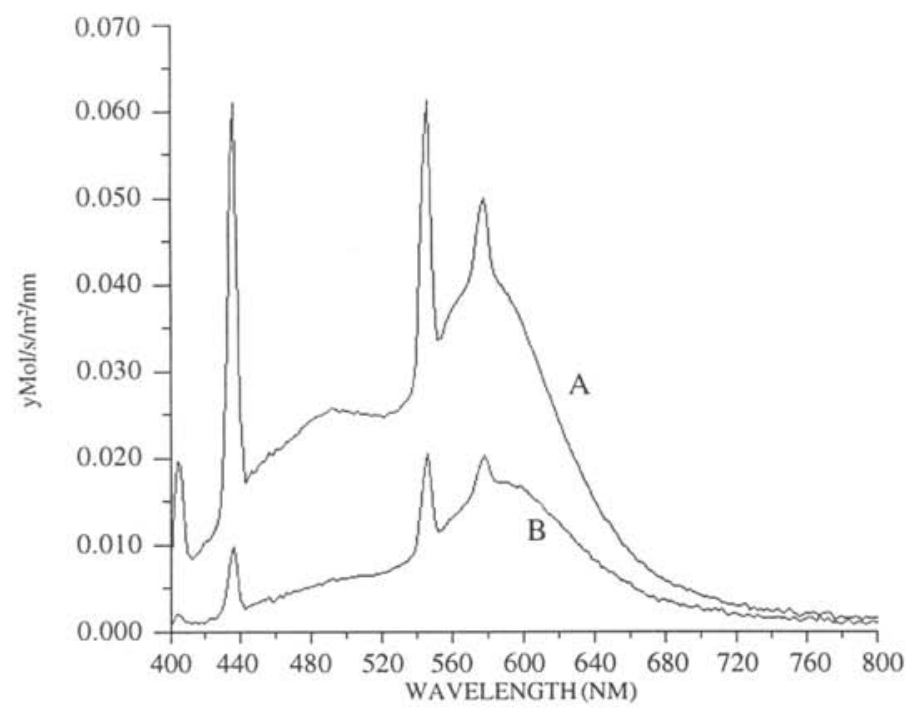

Figure 4. Spectra of white fluorescent light (A) and of transmitted light by the seed coat of Raphanus sativus L. cv. redondo gigante (B).

The ratio of spectrum of white light by spectrum of light transmitted the seed coat indicates that short wavelengths are transmitted more by the seed coat than the long wavelengths which are more active for phytochrome cycling in the high irradiance response (Fig. 5) (Mancinelli 1994).

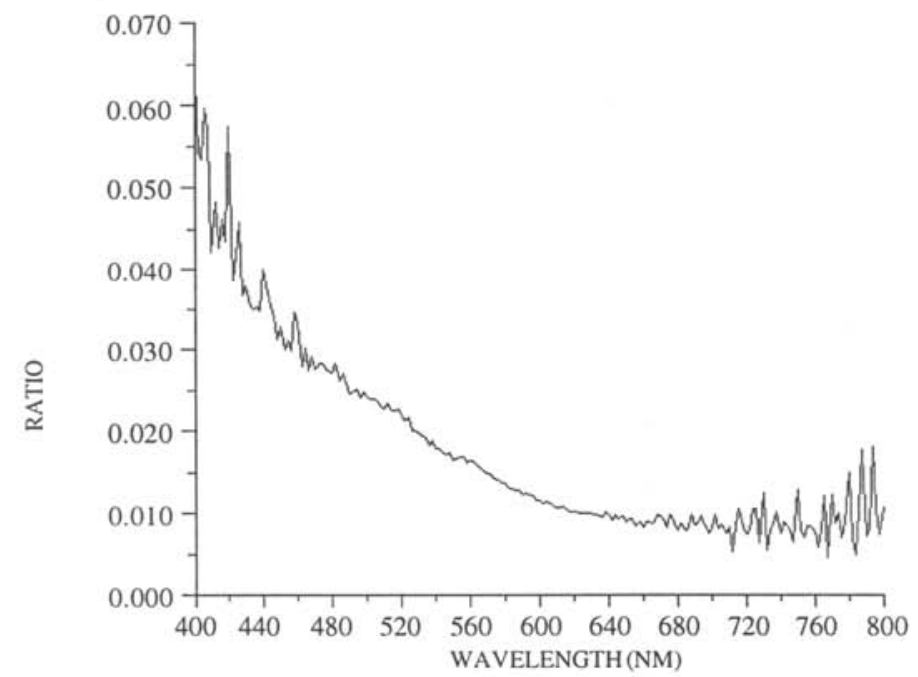

Figure 5. Spectrum ratio of the white fluorescent light and transmitted light by the seed coat of Raphanus sativus $\mathrm{L}$. cv, redondo gigante 
Finally, we have concluded that the Raphanus sativus seed coat has two functions as quantitative filter decreasing the light irradiance which reaches the embryo and resistance for the rupture of the seed coat by the embryo. Under both conditions the phytochrome is involved in the control of seed germination, the decrease in light irradiance by the seed coat induces low phytochrome cycling (Mancinelli 1994) and the resistance to expansion of the embryo presents the same effect of water stress condition which according to Ladeira et al. (1987) the phytochrome is the pigment responsible for the monitoring the soil water status.

\section{Acknowledgements}

M.T. is supported by a CNPq research fellowship. We thank to Dr. Reinaldo Monteiro for the revision of the English manuscript. This work was supported in part by grants from CNPq, FUNDUNESP and FAPESP.

\section{References}

Barbarini, N.R. \& Takaki, M. 1989. Osmotically induced high light sensitivity in seedling of Phaseolus vulgaris. Biologia Plantarum 31: 227-229.

Cardoso, V.J.M. \& Felippe, G.M. 1988. The action of the testa upon the germination of seeds of Cucumis anguria L. Biologia Plantarum 30: 48-52.

Felippe, G.M. \& Polo, M. 1983. Germinação de ervas invasoras: efeito de luz e escarificação. Revista Brasileira de Botânica 6: 55-60.

Freitas, N.P. \& Takaki, M. 1992. Phytochrome controlled seed germination in light insensitive seeds of Raphanus sativus L. cv. redondo gigante. Arquivos de Biologia e Tecnologia 35: 609-612.

Kendrick, R.E. \& Frankland, B. 1969 Photocontrol of germination in Amaranthus caudatus. Planta 85: 326-329.

Ladeira, A.M.; Guardia, M.C. \& Takaki, M. 1987 Manipulation of seed germination in Plantago tomentosa Lam. and Raphanus sativus L. Seed Science and Technology 15: 55-63.

Leite, I.T.A. \& Takaki, M. 1994 Análise da germinação de sementes de Piptadenia gonoacantha (Mart.) Macbr. (Leguminosae - Mimosoideae). Arquivos de Biologia e Tecnologia 37: 587-595.

McDonough, W.T. 1967 Dormant and non dormant similar germination response when osmotically inhibited. Nature 214: 1147-1148.

Mancinelli, A.L. 1994 The physiology of action. In: R.E. Kendrick \& G.H.M. Kronenberg (ed.), Photomorphogenesis in plants 2nd ed., p. 211-269, Kluwer Kluwer Academic Publishers, Dordrecht.

Michel, B.E. 1983 Evaluation of the water potentials of solutions of polyethylene glycol 8000 both in the absence and presence of other solutes. Plant Physiology 72: 66-70.

Takaki, M. \& Toledo, J.C. 1991. Effect of pre-imbibition and scarification on the senstivity to water stress in sees of Oryza sativa L. Seed Science and Technology 19: 263-268. 